Бочарникова Олеся Владимировна, доцент кафедры «Прикладная геодезия, природообустройство и водопользование» ФГБОУ ВО «Волгоградский государственный аграрный университет» (40002, Россия, Волгоград, проспект Университетский, 26), доктор технических наук, доцент, тел. 8 (8442)41-17-84 e-mail: olesya.bocharnikova@mail.ru.

Пустовалов Евгений Васильевич, доцент кафедры «Прикладная геодезия, природообустройство и водопользование» ФГБОУ ВО «Волгоградский государственный аграрный университет» (40002, Россия, Волгоград, проспект Университетский, 26), кандидат сельскохозяйственных наук, тел. 8 (8442)41-81-53 e-mail: pustovalov-evgeniy@mail.ru.

Денисова Мария Алексеевна, старший преподаватель кафедры «Прикладная геодезия, природообустройство и водопользование» ФГБОУ ВО «Волгоградский государственный аграрный университет» (40002, Россия, Волгоград, проспект Университетский, 26), кандидат технических наук, тел. 8 (8442)41-81-53 e-mail: masha2008-1988@mail.ru.

\title{
DOI: 10.32786/2071-9485-2021-02-35 \\ QUALITATIVE INDICATORS OF SPRAYING WHEN USING THE METHOD OF STRIP CHEMICAL TREATMENT OF SUNFLOWER
}

\author{
I.B. Borisenko ${ }^{1}$,, M. V. Meznikova ${ }^{1}$, E. I. Ulybina ${ }^{1}{ }^{3}$ \\ ${ }^{1}$ Volgograd State Agrarian University, Volgograd \\ ${ }^{2}$ CaspianRresearch Institute of Arid Agriculture, Astrakhan region \\ ${ }^{3}$ State Budget Professional Educational Institution \\ «Sebryakovsky Technological College» Volgograd region
}

Received 10.03.2021.

Submitted 15.05.2021

\begin{abstract}
Introduction. This article discusses the qualitative indicators of spraying using the method of strip chemical treatment of sunflower, taking into account the phase of growth and development of the plant. The operation of chemical plant protection in the cost structure is $20 \%$. The difficulties of the operation are associated with many agrotechnological parameters. In order to reduce the cost of the spraying operation, it is necessary to look for new approaches to applying the solution to the plant, depending on the architecture of the structure and the phase of development of the crop. This approach was found as a new technology for the method of strip chemical treatment of high-stemmed crops. The principle of applying the solution to the plant is to redistribute the solution from the untreated strip to the plant, since in the development phase of 6-8 pairs of leaves, the sunflower has a sufficiently high stem, and the weeds are oppressed by the cultivated plant. Therefore, there is no need to carry out a continuous treatment with a chemical solution and row spacing and row. Materials and methods. Measurements of the phase of growth and development of sunflower were carried out during the period from the moment of sowing to harvesting of the crop. To measure the growth of the plant, three sunflower shoots were selected in the middle of the field to exclude the edge effect. The height of the shoot and the width of the leaf layer were measured with a ruler. To assess the quality indicators on the field, a «Hardi» trailed rod sprayer was used, and strips of water-sensitive paper were attached to the leaves to catch drops. The number of drops was calculated using a magnifying glass, as well as using a technique for evaluating the quality indicators of plant protection machines in accordance with GOST. Results. Based on the results of field studies, a graph is constructed that clearly shows the dependence of the growth of the stem and the width of the sunflower leaf layer. The photo evidence of the obtained results of spraying all layers of leaves, stem and back side of the leaf, as well as a photo of applying the solution to the culture directed at an angle of $45^{\circ}$ in the field, with drawing the contour of spraying the working solution over the rows of sunflower. The density of the coating droplets sheet plate calculated by the formula, and based on these data, built surface graph of the number of drops falling on the sheet from its location in the structure of the culture. Discussions and conclusion. The proposed technology of applying the solution to high-stem crops shows that due to the changeover of rod sprayers in the field, the method of strip chemical treatment of row crops is more effective than continuous spraying. This conclusion allows you to do evaluation of quality indicators, which are obtained by forming a more stable flow of working solution, reduce the vertical vibrations of the rod, as well as visual assessment of dispersion of droplets and the dependences of the density of the coating drops of the solution surface of leaves.
\end{abstract}




\section{***** K3BECTKЯ ***** \\ НИЖНЕВОАЖСКОГО АГРОУНИВЕРСИТЕТСКОГО КОМПАЕКСА: \\ НАУКА И ВЫСШЕЕ ПРОФЕССИОНААЬНОЕ ОБРАЗОВАНИЕ}

Key words: sprayer, chemical plant protection, quality of spraying, strip method of chemical treatment, row crops, rod sprayers, sunflower development phases.

Citation. Borisenko, I. B., Meznikova M. V., Ulybina E. I. Qualitative indicators of spraying when using the method of strip chemical treatment of sunflower. Proc. of the Lower Volga Agro-University Comp. 2021.2 (62). 338-347 (in Russian). DOI: 10.32786/2071-9485-2021-02-35.

Author's contribution. All the authors of this article took part in determining the quality indicators of spraying, evaluating and processing the results. The authors reviewed and approved the received version of the article.

Conflict of interest. The authors declare no conflicts of interest.

УДК 632.98631 .348 .45

\section{КАЧЕСТВЕННЫЕ ПОКАЗАТЕЛИ ОПРЫСКИВАНИЯ ПРИ ПРИМЕНЕНИИ СПОСОБА ПОЛОСОВОЙ ХИМИЧЕСКОЙ ОБРАБОТКИ ПОДСОЛНЕЧНИКА}

И. Б. Борисенко ${ }^{1}, 2$, доктор технических наук, старший научный сотрудник

М. В. Мезникова ${ }^{1}$, кандидат технических наук, преподаватель

\section{Е. И. Улыбина ${ }^{1}, \mathbf{3}$, соискатель}

${ }^{1}$ Волгоградский государственный аграрный университет, г. Волгоград, Россия

2Прикаспийский научно-исследовательский институт аридного земледелия,

c. Соленое Займище, Астраханская область, Россия

${ }^{3}$ Государственное бюджетное профессиональное образовательное учреждение «Себряковский технологический техникум», Волгоградская обл., г. Михайловка, Россия

Дата поступления в редакцию 10.03.2021

Дата принятия к печати 15.05.2021

Актуальность. В данной статье рассматриваются качественные показатели опрыскивания с применением способа полосовой химической обработки подсолнечника с учетом фазы роста и развития растения. Операция химической защиты растений в структуре затрат составляет $20 \%$. Трудности проведения операции связывают со многими агротехнологическими параметрами. Для того чтобы снижать затраты на проведение операции опрыскивания, необходимо искать новые подходы к нанесению раствора на растение в зависимости от архитектуры строения и фазы развития культуры. Такой подход был найден в качестве новой технологии способа полосовой химической обработки высокостебельных культур. Принцип нанесения раствора на растение заключается в перераспределении раствора с необрабатываемой полосы на растение, так как в фазе развития 6-8 пар листьев подсолнечник имеет достаточно высокий стебель, и сорняки угнетаются культурным растением. Поэтому нет необходимости проводить сплошную обработку химическим раствором междурядья и ряда, где произрастает культурное растение. При этом с развитием подсолнечника на поверхности листовой пластины и обратной стороне листа наблюдаются болезни и бактерии, которые могут приводить к потере урожая. В этой фазе развития подсолнечнику требуется более тщательная обработка с позиции качества опрыскивания, которую не может обеспечить сплошное опрыскивание, так как при вертикальном распылении раствора листья подсолнечника, расположенные по спирали, будут препятствовать вертикальному полету капель и проникновению раствора в стеблестой. Качество обработки при сплошном распылении будет снижаться, а количество затрат из-за проведения повторных обработок - увеличиваться. Поэтому предлагается модернизировать штанговые опрыскиватели с применением инновационных корпусов-делителей, которые легко устанавливаются в полевых условиях и направляют раствор под углом $45^{\circ}$ на растение из соседних форсунок. Материалы и методы. Замеры фазы роста и развития подсолнечника велись на протяжении с момента посева до уборки урожая культуры. Для замеров роста растения выбиралась три побега подсолнечника в середине поля для исключения краевого эффекты. Высота побега и ширина слоя листьев измерялись линейкой. Для оценки качественных показателей на поле использовался прицепной штанговый опрыскиватель Hardi, а также для улавливания капель на листьях крепились полоски водочувствительной бумаги. Подсчет количества капель произво- 


\section{****** НЗВЕСТИЯ ***** \\ НИЖНЕВОАЖСКОГО АГРОУНИВЕРСИТЕТСКОГО КОМПАЕКСА: НАУКА И ВЫСШЕЕ ПРОФЕССИОНААЬНОЕ ОБРАЗОВАНИЕ}

дили с помощью лупы, а также с применением методики для оценки качественных показателей машин для защиты растений в соответствии с ГОСТ. Результаты. По результатам полевых исследований построен график, наглядно показывающий зависимость роста стебля и ширины слоя листьев подсолнечника. Приведены фотосвидетельства полученных результатов опрыскивания всех слоев листьев, стебля и обратной стороны листа, а также фотография нанесения раствора на культуру, направленного под углом $45^{\circ}$, в полевых условиях с прочерчиванием контура распыления рабочего раствора над рядами подсолнечника. Густота покрытия капель листовой пластины подсчитана по формуле, и на основании этих данных построен поверхностный график зависимости количества капель, попадающих на лист, от его расположения в строении культуры. Обсуждение и выводы. Предложенная технология нанесения раствора на высокостебельные культуры показывает, что за счет переналадки штанговых опрыскивателей в полевых условиях способ полосовой химической обработки пропашных культур более эффективен, чем сплошное опрыскивание. Такой вывод позволяет сделать оценка качественных показателей, которые получаются путем формирования более стабильного потока рабочего раствора, снижения вертикальных колебаний штанги, а также визуальной оценки дисперсности капель и построенной зависимости густоты покрытия каплями раствора поверхности листьев.

Ключевые слова: опрыскиватели, химическая защита растений, качество опрыскивания растений, полосовой способ химической обработки, пропашные культуpы, штанговые опрыскиватели, фазы развития подсолнечника.

Цитирование. Борисенко И. Б., Мезникова М. В., Улыбина Е. И. Качественные показатели опрыскивания при применении способа полосовой химической обработки подсолнечника. Известия НВ АУК. 2021. 2 (62). 338-347. DOI: 10.32786/2071-9485-2021-02-35.

Авторский вклад. Все авторы данной статьи принимали участие в определении показателей качества опрыскивания, и работы в поле, оценке и обработки результатов полевых исследований. Авторы ознакомились и одобрили полученный вариант статьи.

Конфликт интересов. Авторы заявляют об отсутствии конфликта интересов.

Введение. Россия занимает лидирующие позиции как страна, активно наращивающая рынок сельхозсырья и продовольствия. Эти тенденции, по данным экспертноаналитического центра Агробизнеса, сохраняются во всех отраслях пищевой промышленности. Связано это с увеличением объема обрабатываемых площадей и внедрением передовых технологий в процесс выращивания культур и их уборки. Подсолнечник в структуре посевных площадей занимает третье место и составляет 10,6 \% от всех обрабатываемых земель. Такой интерес к данной культуре сельхозпроизводителей обусловливается высокой ценой, которая зависит от качества получаемой конечной продукции и применения новых технологий, позволяющих сокращать затраты при возделывании культуры [6].

При этом подсолнечник остается очень требовательным растением, которое остро реагирует на правильность выбранных подходов при ее производстве [2]. И несоблюдение всех агротехнологических приемов может приводить к большому проценту потери урожая $[9,10]$. Ярким примером значительной доли гибели урожая подсолнечника может быть несоблюдение подходов в проведении операции химической защиты растений или сохранение традиционной химической обработки в качестве сплошного опрыскивания без учета фазы роста и вегетации культуры [5].

Материалы и методы. Для достижения поставленной научной задачи наблюдения за культурой велись на протяжении всего периода вегетации и производились с мая по сентябрь на полях хозяйства «Гелио-Пакс-Агро4» Михайловского района Волгоградской области. В исследованиях применялся сорт подсолнечника «Пионер». Замеры всходов подсолнечника производились с частотой - один раз в две недели. При этом замеры производились в середине поля на трех культурах в разных участках поля. При 
этом для узнаваемости всходы подсолнечника, участвующие в исследованиях, помечались яркими флажками. Замеры велись по таким параметрам, как высота стебля, количество листьев на стебле, ширина слоя листьев, длина и ширина листа. Все результаты фиксировались в ведомости, а затем обрабатывались математическим способом с помощью программы Excel. C применением нового способа нанесения раствора на растение были также проанализированы качественные показатели опрыскивания. Оценивались густота и дисперсный состав осевших капель с помощью карточек водочувствительной бумаги, обработанных 3-5 \% раствором парафина в толуоле для уменьшения растекания капель. Перед проведением опыта учетные карточки размещались на всех ярусах подсолнечника, в том числе на обратной стороне листа и на стебле, а также в междурядье. На одну сторону штангового опрыскивателя устанавливались форсунки с горизонтальным конусом распыла как для сплошного опрыскивания, а на другую устанавливались инновационные корпуса-делители с применением полосового способа нанесения раствора на растение. При проходе штангового опрыскивателя число учетных карточек по ширине захвата определяли с учетом расстановки растения в рядке. А именно за один проход оценивалось 9 насаждений подсолнечника сплошного и полосового опрыскивания. Опыт проводили в трехкратной повторности. Сначала оценивался визуальный эффект присутствия капель на полосках водочувствительной бумаги для всех ярусов сплошного и полосового опрыскивания. По результатам делали сравнительный анализ и вывод фиксировали в ведомости. Затем собранные карточки выкладывали на сухой лист бумаги для предотвращения попадания влаги и оценивали густоту покрытия. Карточки распределяли на 5 групп согласно ГОСТ «Машины для защиты растений»: первая группа - необработанные, вторая группа - с густотой менее чем допустимая, третья группа - с густотой допустимой, четвертая группа - с густотой более чем допустимая, пятая группа - залитые карточки.

Классификацию карточек на группы производили по результатам визуального осмотра и лупы. Группы первая и пятая не анализировались. Остальные с помощью лупы просматривали, подсчитывали количество капель и сравнивали с техническим заданием в ГОСТ, оставляя только карточки с допустимой густотой покрытия.

Результаты и обсуждение. Подсолнечник в начальной стадии развития конкурирует с сорняками, которые в 3-5 раз больше потребляют света, влаги, элементов питания. Поэтому в фазе развития 2-3 пар листьев целесообразно проводить сплошное опрыскивание. Но как только растение достигает фазы развития 6-8 пар листьев при сплошном опрыскивании качество обработки будет снижаться [4]. В этой же фазе необходимо учитывать место локализации и развития болезней и вредителей. Как правило, это обратная сторона листа, которая при сплошном опрыскивании не обрабатывается. В результате этого возникает необходимость повторных операций [7]. При этом агрохимической наукой уже доказана губительность таких явлений, которые нарушают процесс развития подсолнечника и снижают урожайность $[6,8]$. В данном случае сплошное опрыскивание будет иметь слишком много недостатков при развитии высокостебельных культур, которые неблагоприятно сказываются на качестве обработки растения (рисунок 1).

Поэтому для эффективного использования рабочего раствора и успешной борьбы с сорняками, а также болезнями и вредителями, в том числе используя одновременную обработку обратной стороны листа подсолнечника и стебля, для высокостебельных культур необходимо грамотно перераспределить потоки рабочей жидкости [3, 11]. В результате получаем новый способ нанесения раствора на растение за счет перенаправления потоков раствора из соседних форсунок навстречу друг другу под углом $45^{\circ}$ 
[1]. Такого эффекта при опрыскивании подсолнечника можно достичь при помощи модернизации серийных штанговых опрыскивателей с щелевыми форсунками $65^{\circ}$ и $80^{\circ}$ распыла путем установки специальных корпусов-делителей [8, 12]. Инновационные корпуса-делители при работе в поле представлены на рисунке 2.

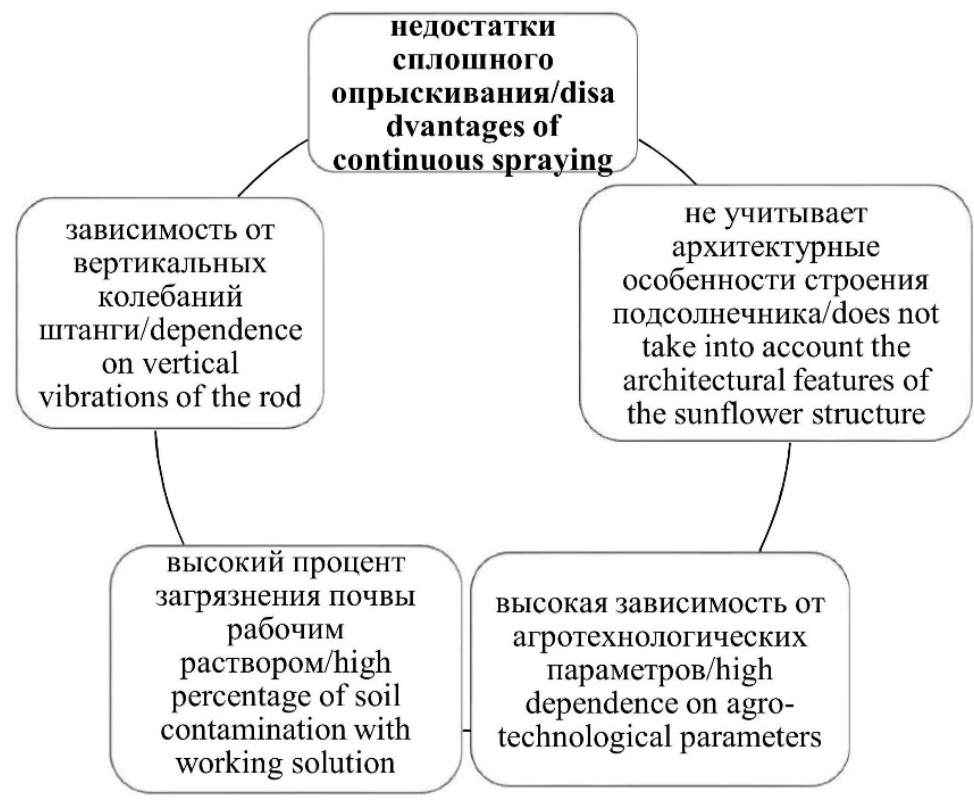

Рисунок 1 - Недостатки сплошного опрыскивания для подсолнечника в фазе развития 6-8 пар листьев

Figure 1 - Disadvantages of continuous spraying for sunflower in the phase of development of 6-8 pairs of leaves

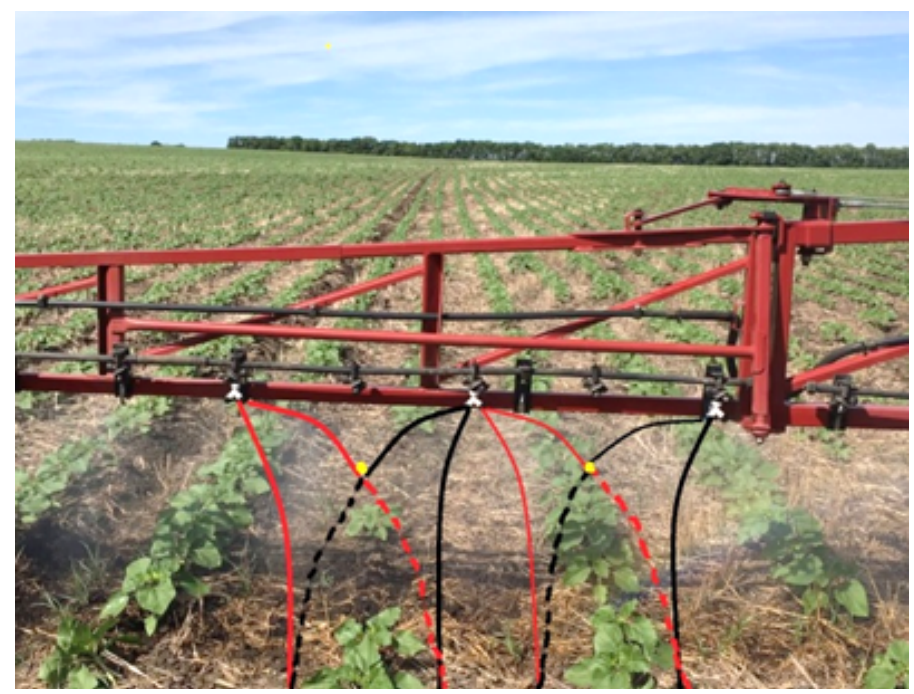

Рисунок 2 - Инновационные корпуса-делители при работе в поле, с распылением потока рабочей жидкости над рядками подсолнечника в фазе развития 5 - 6 пар листьев

Figure 2 - Innovative housing dividers working in the field, with the spray of the working fluid over the rows of sunflower in the development phase of 5-6 pairs of leaves

Новая технология опрыскивания тесно связана с изучением параметров роста подсолнечника, количеством расположения листьев на стебле и шириной яруса листьев. Зависимость архитектурных особенностей подсолнечника от фазы его роста пред- 
ставлена на рисунке 3. Это позволяет убедиться, что листья подсолнечника располагаются по спирали, частично перекрывая поверхности друг друга, препятствуя вертикальному полету капель при проведении операции химической защиты $[2,12]$.

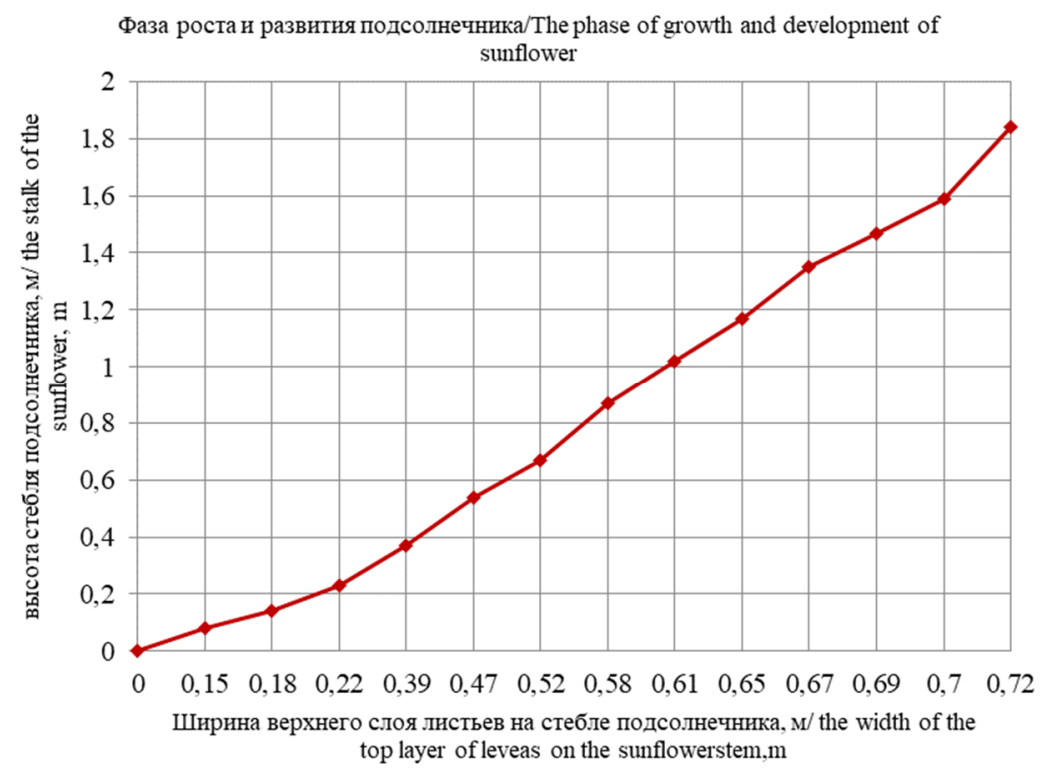

Рисунок 3 - Зависимость архитектурных особенностей подсолнечника от фазы его роста

Figure 3 -Dependence of the architectural features of the sunflower on the phase of its growth

Анализ графика показывает, что при начальной фазе развития кривая графика более пологая. Ширина ярусов листьев находится на одном уровне, но при достижении 0,5-0,6 м кривая растет пропорционально росту стебля и полностью перекрывает слои листьев с шириной 0,15-0,39 м. Следовательно, верхние слои листьев будут препятствовать качественной обработке нижних ярусов раствором.

С применением нового способа нанесения раствора на растение были также проанализированы качественные показатели опрыскивания. Оценивались густота и дисперсный состав осевших капель. На рисунке 4 представлена фотофиксация качественных показателей опрыскивания для полосового способа нанесения раствора после прохода штангового опрыскивателя.

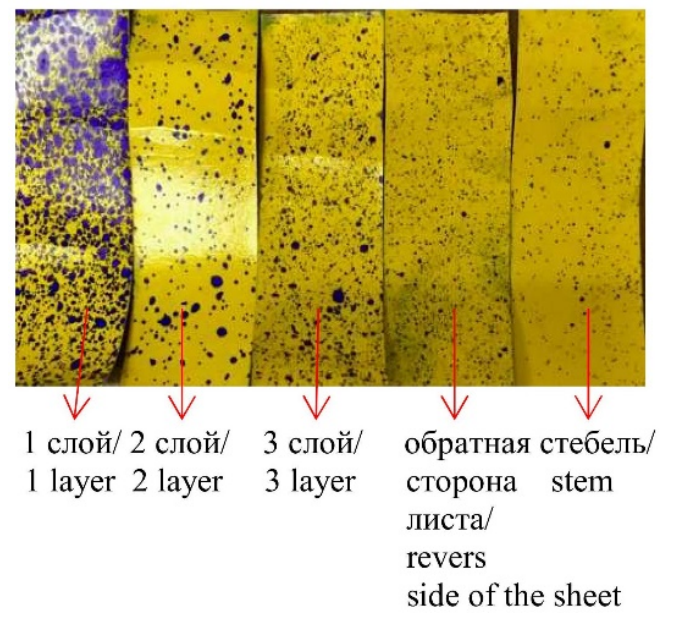

Рисунок 4 - Результаты полосового опрыскивания подсолнечника

Figure 4 - Results of sunflower strip spraying 
После визуального осмотра карточек подсчитывалась густота покрытия капель на площади $1 \mathrm{~cm}^{2}$ по формуле:

$$
\Pi_{\circ}=\frac{N \kappa}{S n},
$$

где $N \kappa$ - общее число учтенных капель; $S n$ - исследуемая площадь, см² $^{2}$

Для этого на каждой карточке с помощью лупы подсчитывали количество капель на определенной площади, результаты обрабатывали и заносили в ведомость испытаний. На сновании проведенных полевых исследований построили график густоты покрытия листовой пластины каплями раствора на площади $1 \mathrm{~cm}^{2}$ в зависимости от расположения слоев листьев на стебле (рисунок 5).

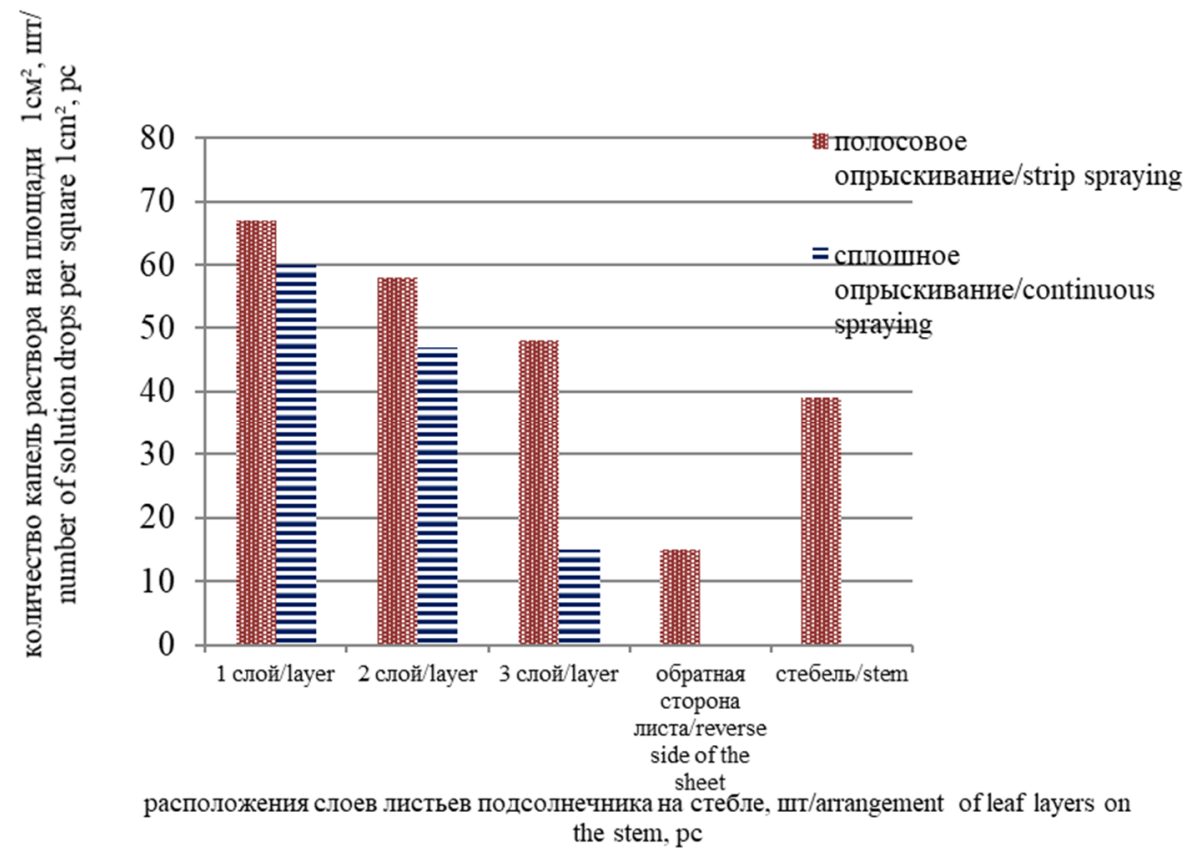

Рисунок 5 - Густота покрытия листовой пластины каплями раствора на площади $1 \mathrm{~cm}^{2}$ в зависимости от расположения слоев листьев на стебле для сплошного и полосового опрыскивания

Figure 5 - The density of the coating of the leaf plate with drops of solution on an area of $1 \mathrm{~cm}^{2}$, depending on the location of the layers of leaves on the stem for continuous and strip spraying

Выводы. Обработка результатов позволяет сделать вывод, что капли наблюдаются по всей поверхности листовой пластины. Они имеют мелкодисперсный, однородный, равномерный характер. Количество капель на листе снижается в зависимости от расположения листа на стебле. Меньшее их количество наблюдается на обратной стороне листа и на стебле, но при этом качество обработки улучшается в общем объеме, так как раствор достигает своей цели, не встречая препятствий на своем пути, как это происходит при сплошной обработке.

Применение метода оценки качества опрыскивания способа полосовой химической обработки растений на примере подсолнечника с использованием тестовых полосок показал преимущества данного способа по сравнению со сплошным опрыскиванием, а установка инновационных корпусов-делителей с ориентированными навстречу друг другу факелами распыла способствует созданию более стабильного потока и повышению качества обработки посевов. 
Библиографический список

1. Борисенко И. Б., Мезникова М. В., Улыбина Е. И. Новые технологии применения опрыскивателя // Сельский механизатор. 2019. № 8. С. 4-5,13.

2. Борисенко И. Б., Мезникова М. В., Улыбина Е. И. Научные аспекты технической модернизации опрыскивателей для химической защиты подсолнечника // Известия Нижневолжского агроуниверситетского комплекса: наука и высшее профессиональное образование. 2020. № 4 (60). C. 1-11.

3. Варфоломеева М. М., Фомина И. В. Из опыта модернизации прицепного штангового опрыскивателя // Всероссийский научно-исследовательский институт механизации и информатизации агрохимического обеспечения сельского хозяйства. 2017. № 11. С. 128-134.

4. Данилов М. В., Абаев В. В. Особенности технологии защиты растений с применением штанговых опрыскивателей и ее недостатки // Вестник научных конференций. 2019. № 3-1(43). C. 46-47.

5. Киреев И. М., Коваль 3. М. Результаты моделирования технологического процесса распределения капельной жидкости между распылителями штанговых опрыскивателей // Техника и оборудование для села. 2018. № 12. С. 16-21.

6. Лукомец В. М., Пивень В. Т., Тишков Н. М. Защита подсолнечника от вредителей и болезней // Защита и карантин растений. 2017. № 5. С. 14-16.

7. Мамедов 3. В. Исследование потерь рабочей жидкости из наконечников при неработающем насосе штанговых опрыскивателей для обоснования применения обратного клапана к каждому // Аграрная наука. 2020. № 2. С. 81-84.

8. Повышение эффективности химической обработки пропашных культур в рамках полосовой технологии / М. В. Мезникова, И. Б. Борисенко, Е. И. Улыбина, О. В. Бояркина // Вестник РУ ДН. Серия: Агрономия и животноводство. 2019. Т. 14. № 4. С. 453-465.

9. Фомина И. В., Варфоломеева М. М. Современное состояние и тенденции развития техники для химической защиты растений // Проблемы механизации агрохимического обеспечения сельского хозяйства: Всероссийский научно-исследовательский институт механизации и информатизации агрохимического обеспечения сельского хозяйства. 2017. № 11. С. 182-189.

10. 5-point program for sustainable plant protection / T. Frische, S. Eherer, Sh. Of. Matesky, K. Pickle, Th. Vogram // Environmental Sciences Europe. 2018. V. 30. No 8. https://doi.org/10.1186/s12302-018-0136-2.

11. Ghasemzadeh H. R., Humburg D. Using fan nozzles with adjustable spray angle on long rods // Agricultural Engineering International: CIGR Journal. 2016. Vol. 18. P. 80-92.

12. Methods and applications of new technologies used for reducing of chemical usage and controlling of pests (a review) / M. A. Ebrahimi, M. H. Khoshtaghaza1, S. Minaei1, B. Jamshidi // Agricultural Engineering International: CIGR Journal. 2018. Vol. 20. No. 2. P. 144-154.

13. Resource-saving method of chemical treatment of tilled crops / I. B. Borisenko, A. S. Ovchinnikov, M. V. Meznikova, S. D. Fomin, V. S. Bocharnikov, A. F. Rogachev, E. I. Ulybina // Conference on Innovations in Agricultural and Rural development IOP Conf. Series: Earth and Environmental Science. 2019.

Conclusion. Processing the results allows us to conclude that the drops are observed over the entire surface of the sheet plate. They have a fine, uniform, uniform character. The number of drops on the leaf decreases depending on the location of the leaf on the stem. Fewer of them are observed on the reverse side of the leaf and on the stem, but the quality of processing improves in the overall volume, as the solution reaches its goal without encountering obstacles in its path, as it happens with continuous processing. The application of the method for assessing the quality of spraying of the method of strip chemical treatment of plants, for example, sunflower with the use of dough strips, showed the advantages of this method compared to continuous spraying, and the installation of innovative divider housings with spray torches oriented towards each other contributes to the creation of a more stable flow and improving the quality of crop treatment 


\section{***** I3BECTYЯ ***** \\ НИЖНЕВОАЖСКОГО АГРОУНИВЕРСИТЕТСКОГО КОМПАЕКСА \\ НАУКА И ВЫСШЕЕ ПРОФЕССИОНААЬНОЕ ОБРАЗОВАНИЕ \\ References}

1. Borisenko I. B., Meznikova M. V., Ulybina E. I. New technologies for the use of spraying // Rural machine operator. 2019. No. 8. P. 4-5,13.

2. Borisenko I. B., Meznikova M. V., Ulybina E. I. Scientific aspects of technical modernization of sprayers for chemical protection of sunflower // Izvestia of the Lower Volga Agro-University Complex: nauka i vysshee professional obrazovanie. 2020. No. 4 (60). P. 1-11.

3. Varfolomeeva M. M., Fomina I. V. From the experience of modernization of a trailed barbell sprayer // Russian Research Institute of Mechanization and Informatization of Agricultural Chemical Support of Agriculture. 2017. No. 11. P. 128-134.

4. Danilov M. V., Abaev V. V. Features of plant protection technology using barbell sprayers and its shortcomings // Bulletin of scientific conferences. 2019. No. 3-1 (43). P. 46-47.

5. Kireev I. M., Koval Z. M. Results of modeling the technological process of distribution of drip liquid between sprayers of rod sprayers // Technika i oborudovanie dlya sela. 2018. No. 12. P. 16-21.

6. Lukomets V. M., Piven V. T., Tishkov N. M. Protection of sunflower from pests and diseases // Protection and quarantine of plants. 2017. No. 5. P. 14-16.

7. Mammadov Z. V., Investigation of losses of working fluid from handpieces at a nonworking pump of rod sprayers for substantiating the application of a check valve to each // Agrarian Science. 2020. No. 2. P. 81-84.

8. Improving the efficiency of chemical treatment of pro-arable crops within the framework of strip technology / M. V. Meznikova, I. B. Borisenko, E. I. Ulybina, O. V. Boyarkina // Bulletin RUDN. Series: Agronomy and animal husbandry. 2019. V. 14. No. 4. P. 453-465.

9. Fomina I. V., Varfolomeeva M. M. Current state and trends in the development of technology for chemical plant protection // Problems of mechanization of agrochemical support of agriculture: All-Russian Research Institute for Mechanization and informatting of agrochemical support of agriculture. 2017. № 11. P. 182-189.

10. 5-point program for sustainable plant protection / T. Frische, S. Eherer, Sh. Of. Matesky, K. Pickle, Th. Vogram // Environmental Sciences Europe. 2018. V. 30. No 8. https://doi.org/10.1186/s12302-018-0136-2.

11. Ghasemzadeh H. R., Humburg D. Using fan nozzles with adjustable spray angle on long rods // Agricultural Engineering International: CIGR Journal. 2016. Vol. 18. P. 80-92.

12. Methods and applications of new technologies used for reducing of chemical usage and controlling of pests (a review) / M. A. Ebrahimi, M. H. Khoshtaghaza1, S. Minaei1, B. Jamshidi // Agricultural Engineering International: CIGR Journal. 2018. Vol. 20. No. 2. P. 144-154.

13. Resource-saving method of chemical treatment of tilled crops / I. B. Borisenko, A. S. Ovchinnikov, M. V. Meznikova, S. D. Fomin, V. S. Bocharnikov, A. F. Rogachev, E. I. Ulybina // Conference on Innovations in Agricultural and Rural development IOP Conf. Series: Earth and Environmental Science. 2019.

\section{Authors information}

Borisenko Ivan Borisovich, doctor of technical Sciences, senior researcher, Department of agriculture and Agrochemistry, Volgograd state agrarian University, Volgograd, Russia, Caspian research Institute of arid agriculture, Salt zaymishche village, Astrakhan region, (Russia, 400002, Volgograd region, Volgograd, 26 pr. Universitetskiy) https://www.orcid-ru.org/ 0000-0002-6486-9210, t.+7 (8442) 41-12-20, +7 (902) 38729-42, E-mail: borisenivan@yandex.ru

Meznikova Marina Viktorovna candidate of technical Sciences, teacher, Department of life safety, Volgograd state agrarian University, Volgograd (Russia, 400002, Volgograd region, Volgograd, 26 pr. Universitetskiy), https://www.orcid-ru.org/ 0000-0002-9384-7766, t.+7 (8442) 41-15-18, +7(960)883-09-50, E-mail: marina_roxette@mail.ru

Ulybina Ekaterina Ivanovna, teacher GBPOU «Sebryakovsky technological technical»

(Russia, 403345, Volgograd region, Mikhaylovka,146a Communesreet), https://www.orcid-ru.org/00000002-3523-478t.+7(905)434-39-16, E-mail: ulibina.ekat@yandex.ru

\section{Информация об авторах:}

Борисенко Иван Борисович, доктор технических наук, старший научный сотрудник кафедры «Земледелие и агрохимия», ФГБОУ ВО Волгоградский государственный аграрный университет, г. Волгоград, Россия, Прикаспийский научно-исследовательский институт аридного земледелия, с. 
Соленое Займище, Астраханская область (РФ, 400002, Волгоградская обл., г. Волгоград, пр. Университетский, д. 26) https://www.orcid-ru.org/ 0000-0002-6486-9210, т. +7 (8442) 41-12-20, +7 (902) 387-29-42, E-mail: borisenivan@yandex.ru

Мезникова Марина Викторовна, кандидат технических наук, преподаватель кафедры «Безопасность жизнедеятельности» ФГБОУ ВО Волгоградский государственный аграрный университет, (РФ, 400002, Волгоградская обл., г. Волгоград, пр. Университетский, д. 26), https:/www.orcid-ru.org/ 0000-0002-9384-7766, т.+7 (8442) 41-15-18,+7(960)883-09-50, E-mail: marina_roxette@mail.ru

Улыбина Екатерина Ивановна, преподаватель ГБПОУ «Себряковский технологический техникум» (РФ, 403345, Волгоградская обл., г. Михайловка, ул. Коммуны д. 146 a), https://www.orcidru.org/ 0000-0002-3523-4478 т. +7(905)434-39-16,

E-mail: ulibina.ekat@yandex.ru

\title{
THEORETICAL AND EXPERIMENTAL METHOD FOR PREDICTION WEAR OF CHISEL BITS
}

\author{
D.S. Gapich, V. A. Motorin, R.N. Oleinikov \\ Volgograd State Agrarian University, Volgograd
}

Received 30.10.2020

Submitted 25.05.2021

\section{The research was conducted as a part of the grant of the President of the Russian Federation MK-2870.2019.8}

\section{Summary}

Consider modeling the process of wear of the working parts of chisel plow based on the gradual wear of the working parts: the first stage is associated with the formation of the geometry of the bow that provides minimal resistance when moving the working part to the processed material; the second stage is a translational displacement of the obtained cross-section to ultimate limit state. The equation of the wear curve of the working parts of a chisel plow is obtained.

\begin{abstract}
Introduction. The main agricultural tool used in the non-shaft method of processing is chisel plows, which can provide deep loosening of the soil. One of the most heavily loaded parts of the chisel plow are the working parts, since the technical resource of the entire tillage unit depends on them. Premature failure is associated with the process of abrasive wear that occurs when the chisel plow bit interacts with solid soil particles. Reducing the cost of tillage during chiseling and planning the technical resource of agricultural tool parts in real working conditions are topical issues of crop cultivation.

Materials and methods. Two samples of chisel plow chisel were examined. The first sample is made of high-strength cast iron of the HF 50 brand (composition in \%: $3.39 \mathrm{C} ; 0.51 \mathrm{Mn} ; 2.71 \mathrm{Si} ; 0.041 \mathrm{~S}$ ), the second is made of steel 45 , hardened according to the mode. The main laboratory and field studies were carried out at the Educational research and production center «Gornaya Polyana», on classic light chestnut (Calcic Kastanozem) soils with a resistivity coefficient of 7-12, a low content of organic residues (humus-1.5-2.5\%), and a humidity of $8-10 \%$. Tests of the working parts of the chisel plow were carried out to the limit of wear. The General test conditions on average correspond to the typical relief of the Volgograd region, the type and physical and mechanical properties of the soil and other criteria for the quality of work. Both types of test bits were simultaneously installed on one unit, with the possibility of their distribution across the housings depending on the degree of load, to achieve the most equal working conditions. Results and conclusions. To assess the end of the service life of experimental chisels, the maximum wear of the linear size of the bow was used, with a decrease in the linear indicator in this section, the wear was transferred to the rack of the chisel plow, due to which the working part is attached to the frame of the tillage tool. Modeling the wear process of chisel plow bits becomes difficult, since depending on the selected field, and often within the same field, the soil has different physical and mechanical properties and granulometric composition. They differ depending on
\end{abstract}

